\title{
A Systematic Review and Meta-Analysis of Intraperitoneal Bupivacaine in Laparoscopic Gynecologic Surgery
}

\author{
Greg Marchand (1D) \\ Kelly Ware ${ }^{1,2}$ \\ Malini Govindan' \\ Ahmed T Masoud ${ }^{1,3}$ \\ Alexa King ${ }^{1,2}$ \\ Stacy Ruther' \\ Giovanna Brazil \\ Kaitlynne Cieminski' \\ Nicolas Calteux' \\ Catherine Coriell' \\ Hollie Ulibarri' \\ Julia Parise' \\ Amanda Arroyo' \\ Diana Chen ${ }^{4}$ \\ Maria Pierson ${ }^{4}$ \\ Rasa Rafie ${ }^{5}$ \\ Katelyn Sainz'
}

'Marchand Institute for Minimally Invasive Surgery, Mesa, AZ, USA; ${ }^{2}$ International University of Health Sciences, Basseterre, St. Kitts; ${ }^{3}$ Fayoum University Faculty of Medicine, Fayoum, Egypt; ${ }^{4}$ Midwestern University College of Osteopathic Medicine, Glendale, AZ, USA; ${ }^{5}$ Rocky Vista University College of Osteopathic Medicine, Parker, CO, USA

Correspondence: Greg Marchand Marchand Institute for Minimally Invasive Surgery, 10238 E. Hampton, Ste. 2I2,

Mesa, AZ, 85209, USA

$\mathrm{Tel}+\mid 4809990905$

Fax + | 480999080 I

Email gm@marchandinstitute.org
Objective: We set out to evaluate whether the instillation of bupivacaine versus a saline solution into the peritoneal cavity at time of laparoscopic gynecologic surgery will reduce postoperative pain and postoperative opioid consumption.

Data Sources: We searched six databases: Web of Science, SCOPUS, Cochrane CENTRAL, ClinicalTrials.Gov, MEDLINE and PubMed. Our search strategy had no restriction on time or languages and included all studies that met our search algorithm up to March of 2021.

Methods of Study Selection: We included only randomized trials that met our search strategy for the outcomes of 1) pain intensity 24 hours after surgery, 2) pain intensity 6 hours after surgery, and 3) length of hospital stay.

Tabulation, Integration, and Results: We analyzed continuous data using mean difference (MD) with relative $95 \%$ confidence interval (CI). We included 8 randomized clinical trials. We found that intraperitoneal bupivacaine showed significant difference from the saline group regarding pain intensity 24 hours after surgery $(\mathrm{MD}=-0.73[-1.10,-0.36])(\mathrm{P}=0.01)$ and pain intensity 6 hours after surgery $(\mathrm{MD}=-1.12[-2.22,-0.02])(\mathrm{P}=0.05)$. Overall, patients allocated to the placebo group seemed to need other analgesics earlier than patients allocated to the bupivacaine group $(\mathrm{MD}=145.08[51.37,238.79](\mathrm{P}=0.02))$. There was no significant difference regarding the length of hospital stay $(\mathrm{MD}=-0.44[-1.44,0.56])(\mathrm{P}=0.39)$.

Conclusion: Bupivacaine significantly reduced the visual analog pain score for pain compared with that of the placebo at 6 and 24 hours postoperatively. There was no significant difference in hospital stay.

Prospero Registration: CRD42021254268.

Keywords: ERAS, marcaine, bupivacaine, enhanced recovery after surgery, intra-abdominal anesthetic

\section{Introduction}

Gynecologic surgery is very prevalent in the United States, comprising $26.5 \%$ of all surgeries performed on women. ${ }^{1}$ Postoperative pain is one of the most important complications of gynecologic surgeries. Approximately $86 \%$ of patients suffer from postoperative pain, and about $75 \%$ of those report that the pain is moderate to severe. ${ }^{2}$ Improvements in postoperative pain management could lead to shorter hospital stays, decreased costs, earlier mobilization and prevention of thrombosis, and decreased morbidity. ${ }^{3,4}$ Chronic postoperative pain increases sympathetic tone, which in turn may increase molecular catabolism, resulting in abnormal muscle functioning. ${ }^{5}$ Substantial pain after laparoscopic gynecologic surgeries may require 
large doses of opioids in the first 24 hours after the procedure, which can lead to the additional complications of opioid tolerance and habituation. ${ }^{6}$ Several authors have suggested that the administration of local analgesics may reduce the total need for opioids in the first 24 hours postoperatively. $^{7}$ Preemptive anesthesia has been attempted in many forms, including local injection at the surgery site, epidural, or in a systematic manner just before surgical incision. ${ }^{8,9}$ Local anesthetics can also be injected at incisional sites and placed intraperitoneal in an attempt to decrease both visceral and somatic pain. ${ }^{10}$

Despite the fact that many different local anesthetics have been attempted in the preoperative, intraoperative, and postoperative periods, there remains no clear consensus as to the best local anesthetic or the best route of administration. $^{11,12}$ Some authors have suggested simply pouring local anesthetics into the abdominal cavity, as the majority of the patient's pain in the postoperative period does seem deep in the abdomen following laparoscopy. ${ }^{13}$ Some authors have discussed that this method may decrease patient safety as abdominal anesthetics likely have higher intravascular absorption than other methods of administration. ${ }^{14}$ Cases of toxicity have been reported, a specific syndrome of local anesthetic systemic toxicity (LAST) has been described. ${ }^{14}$

Bupivacaine is a long acting, potent local anesthetic agent that is commonly used in gynecologic surgery. ${ }^{15-18}$ In this meta-analysis, we evaluate whether the intraperitoneal placement of a bupivacaine solution versus a saline solution reduces postoperative pain in women undergoing laparoscopic gynecologic surgery, and whether there is a decrease in hospital stay, or time until first required opioid administration.

\section{Methods}

Strict adherence was undertaken in every stop of our metaanalysis and systematic review. As guidelines for this undertaking we used the checklist for "Preferred Reporting Items for Systematic Reviews and Meta-analyses" (PRISMA), and followed all steps to the letter. ${ }^{19}$ Every step of this systematic review was also performed in complete concordance with the instructions included in Cochrane's "handbook of systematic reviews of interventions". 20

\section{Literature Search}

We searched Web of Science, SCOPUS, Cochrane CENTRAL, ClinicalTrials.Gov, MEDLINE and PubMed, for published trials without any restrictions on time or languages. We used the following search strategy: (marcaine OR Bupivacaine OR Sensorcaine OR Posimir) AND (“gynecologic surgery”).

\section{Inclusion Criteria}

The following five criteria were utilized to define eligibility: (I) Patient Population: all female patients undergoing a laparoscopic gynecologic surgery. (ii) Intervention: Bupivacaine (iii) comparator: Placebo. (IV) Outcomes: Pain intensity 24 hours after surgery, Pain intensity 6 hours after surgery, elapsed time for the first non-local analgesic dose, and length of hospital stay. (v) Study design: Only randomized controlled trials were included in our study (RCTs). We excluded any clinical trials that were non-randomized, trials that did not measure for our selected outcomes, studies whose participants were healthy volunteers without surgical intervention, studies without a control group, and animal studies.

\section{Screening of Results}

We scanned the reference list of retrieved studies using Endnote software. Following the automatic deletion of all duplicate studies, we looked at the remaining studies using a two step process. This included first looking at the abstract, and then only moving on to a full text screening on those articles that were found in the first step to meet our criteria.

\section{Data Extraction and Analysis}

Two independent authors extracted the data from the included studies. We extracted the data of all of the major categories required in this work. This included 3 basic categories of data as follows:

1) Demographic data of the patients in each of the included studies. This included body mass index (BMI), patient age, surgery performed, and the duration of the surgery in minutes.

2) Outcome data for our meta-analysis: Pain intensity 24 hours after surgery, pain intensity 6 hours after surgery, elapsed time until the first analgesic dose, and length of hospital stay.

3) Data about the risk of bias from each study, in order to complete Cochrane's risk of bias analysis of our review.

\section{Analysis of Data}

RevMan (version 5.4.1) was utilized in order to perform the meta-analysis. The inverse variance method was used. Data for continuous outcomes were extracted and pooled using the techniques of mean difference (MD) and standard deviation, 
relative to a ninety-five percent confidence interval $(\mathrm{CI})$, while data for those outcomes which were dichotomous were extracted and reported using percent and total. We assessed heterogeneity among studies ${ }^{21}$ by visual inspection of the forest plots, the I-square test (I2), and the P-value of the Chisquare test. The overall analysis of outcomes in the cases where $\mathrm{I}^{2}>50 \%, \mathrm{P}<0.1$ were considered heterogeneous, and those values where $\mathrm{I}^{2}<50 \%, \mathrm{P}>0.1$ were considered homogeneous, as is suggested in adhering to the "The Cochrane Handbook" ${ }^{20}$ We performed an analysis of the homogeneous outcomes under a fixed-effects model using the Mantel Haenszel (M-H) method, while those outcomes that were heterogeneous were analyzed using the "random-effects" model.

\section{Quality Assessment}

To assess the risk of bias of the included randomized clinical trials, we conducted the quality assessment of this study according to the Cochrane Handbook for Systematic Reviews of Interventions 5.1.0 (updated March 2011). We used Cochrane's risk of bias assessment tool ${ }^{22}$ which includes the following domains: sequence generation (selection bias), allocation sequence concealment (selection bias), blinding of participants and personnel (performance bias), blinding of outcome assessment (detection bias), incomplete outcome data (attrition bias), selection outcome reporting (reporting bias), and other potential sources of bias.

\section{Results}

\section{Summary of Included Clinical Trials}

The electronic search results are described in detail in Figure 1, which shows a PRISMA diagram of our search and screening process. We performed the analysis of 532 patients undergoing different laparoscopic gynecological surgeries from eight studies, ${ }^{23-30}$ with a total of 265 patients allocated to the bupivacaine group, and 267 patients allocated to the placebo group. The average age of participants in the bupivacaine group was 37.08 years and the average age of the placebo group was 37.58 years. Table 1 shows a complete summary of the included patients, including their demographic data, body mass index (BMI), and the duration of surgery.

\section{Results of Risk of Bias Assessment}

The overall quality assessment was a low risk of bias according to Cochrane's tool. ${ }^{20}$ All studies ${ }^{23-30}$ were at low risk of bias regarding randomization, blinding of participants and personnel, attrition, and selective reporting bias. Concerning allocation concealment, 5 studies $^{23,25-27,30}$ reported proper allocation concealment, and therefore they were judged to be at low risk of bias. Three studies ${ }^{24,28,29}$ did not report enough data about concealment so they were categorized as an unclear risk of bias. Concerning blinding of outcome assessment, three studies $^{23,27,30}$ revealed adequate blinding of the outcome assessors so they were categorized as low risk of bias, while the remaining studies ${ }^{24-26,28,29}$ were categorized as an unclear risk of bias. Supplemental File 1 shows an illustration of the individual risks of bias of the included studies.

\section{Analysis of Outcomes}

\section{Pain Intensity 24 Hours After Surgery}

Six studies ${ }^{23,24,26,27,29,30}$ reported VAS pain scores after 24 hours. The overall estimate favored the bupivacaine group significantly $(\mathrm{MD}=-0.73[-1.10,-0.36],(\mathrm{P}=0.01))$. We found significant heterogeneity $(\mathrm{P}=0.01) ; \mathrm{I}^{2}=66 \%$ (Figure 2A). In order to solve heterogeneity, we excluded Badawy $2017^{24}(\mathrm{P}=0.12) ; \mathrm{I}^{2}=45 \%$. Pooled analysis after solving heterogeneity also favored the bupivacaine group significantly $(\mathrm{MD}=-0.66[-0.93,-0.39],(\mathrm{P}=0.01))$ (Figure $2 \mathrm{~B})$.

\section{Pain Intensity 6 Hours After Surgery}

Five studies ${ }^{23,24,28-30}$ reported VAS pain scores after six hours. Pooled analysis showed that bupivacaine was superior to placebo in reducing pain after six hours $(\mathrm{MD}=-1.12[-2.22$, $-0.02], \mathrm{P}=0.05)$. Data was heterogeneous $(\mathrm{P}=0.03)$; $\mathrm{I}^{2}=81 \%$ as shown in Figure $3 \mathrm{~A}$. We solved the heterogeneity by excluding Arden et $\mathrm{al}^{23}(\mathrm{P}=0.59) ; \mathrm{I}^{2}=0 \%$. The combined analysis after solving heterogeneity also favored the bupivacaine group significantly $(\mathrm{MD}=-1.85[-2.15,-1.55])$ as shown in Figure 3B.

\section{Length of Hospital Stay (Hours)}

Two studies ${ }^{23,27}$ reported the length of hospital stay. The overall estimate showed no significant difference between either group $(\mathrm{MD}=-0.44[-1.44,0.56],(\mathrm{P}=0.39))$. No significant heterogeneity was found between studies $(\mathrm{P}=0.27) ; \mathrm{I}^{2}=16 \%$ as shown in Figure 4.

\section{Elapsed Time Prior to the First Non-Local Analgesic Dose (in Minutes)}

Three studies estimated the elapsed time prior to the first non-local analgesic dose, ${ }^{24-26}$ and the analysis showed that patients allocated to placebo group needed analgesics earlier than patients allocated to bupivacaine group $(\mathrm{MD}=145.08$ [51.37, 238.79], $(\mathrm{P}=0.02))$. Pooled analysis was heterogeneous $\left.(\mathrm{P}<0.01) ; \mathrm{I}^{2}=97 \%\right)$ as seen in 
Identification

\section{Screening}

Eligibility

\section{Included}

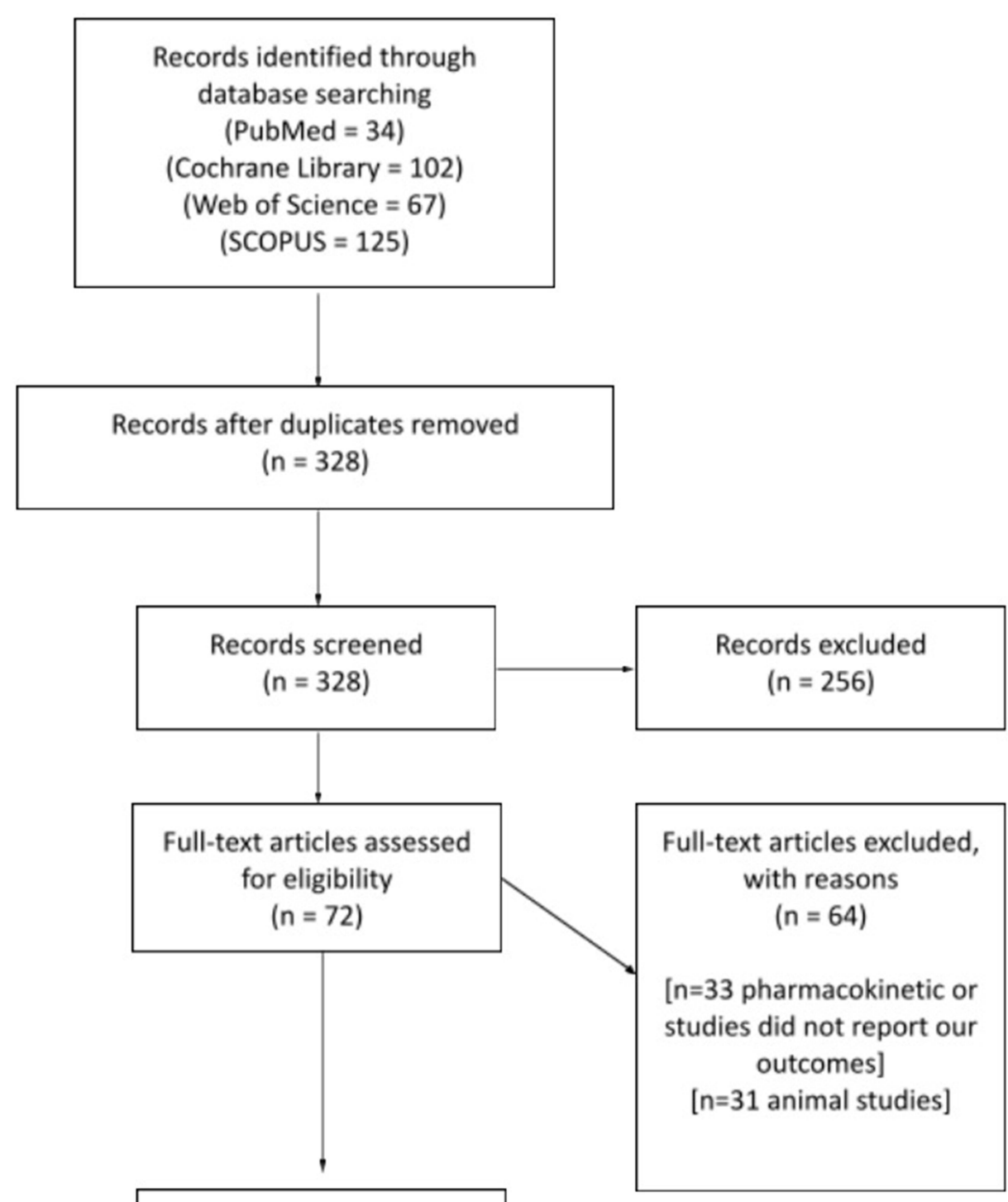

Studies included in quantitative synthesis

(meta-analysis)

$(n=8)$

Figure I Shows a PRISMA flow diagram of our literature search.

Figure 5A. We solved heterogeneity by leaving out Karsli et al $2003^{25}(\mathrm{P}=0.50) ; \mathrm{I}^{2}=0 \%$. The analysis after solving heterogeneity also favored bupivacaine the group significantly $(\mathrm{MD}=192.54$ [167.25, 217.84], $(\mathrm{P}<0.01))$ as shown in Figure 5B.

\section{Discussion}

In this systematic review, we included 8 randomized clinical trials that evaluated the effect of intra-abdominal local analgesic on postoperative pain after various laparoscopic gynecological surgeries. Our meta-analysis showed a significant reduction in VAS score for pain in the bupivacaine group compared with that of the placebo at 6 and 24 hours postoperatively.

A previous meta-analysis performed by Marks et $\mathrm{al}^{31}$ suggested that intraperitoneal local analgesia was very effective in the reduction of postoperative pain at 2 and 6 hours after Laparoscopic Gynecologic surgery, and that bupivacaine did not seem to have any major side effects. These results were consistent with our findings. The major 
Table I Detailed Summary of the Included Participants, Their Demographic Data, and Types of Operations

\begin{tabular}{|c|c|c|c|c|c|c|c|c|}
\hline \multirow[t]{2}{*}{ Study } & \multicolumn{2}{|c|}{ Sample Size } & \multicolumn{2}{|c|}{ Age, Years (Mean \pm SD) } & \multicolumn{2}{|c|}{ BMI $(\mathrm{Kg} / \mathrm{m} 2)$} & \multicolumn{2}{|c|}{ Operation Time (mins) } \\
\hline & Bupivacaine & Control & Bupivacaine & Placebo & Bupivacaine & Placebo & Bupivacaine & Placebo \\
\hline Arden $2013^{23}$ & 80 & 80 & $44.1 \pm 6.4$ & $44.9 \pm 7.1$ & $28.4 \pm 7.6$ & $27.4 \pm 5.9$ & $124.7 \pm 34 . \mid$ & $126.7 \pm 35$ \\
\hline Badawy $2017^{24}$ & 10 & 10 & $46.40 \pm 3.21$ & $46.20 \pm 4.32$ & $31.60 \pm 1.14$ & $30.00 \pm 2.67$ & $132.00 \pm 30.33$ & $137.00 \pm 4 \mid .65$ \\
\hline Butala $2013^{26}$ & 30 & 30 & $34.3 \pm 9.26$ & $33.7 \pm 7.69$ & NR & NR & I $\mid 4.7 \pm 40.88$ & $115.3 \pm 16.28$ \\
\hline Chou $2005^{27}$ & 30 & 31 & $31.6 \pm 7.9$ & $35.1 \pm 11.0$ & $22.8 \pm 3.5$ & $21.5 \pm 3.7$ & $96.42 \pm 29.44$ & $88.96 \pm 30.08$ \\
\hline Karsli $2003^{25}$ & 20 & 20 & $38.7 \pm 7.8$ & $39.8 \pm 8.3$ & NR & NR & $48.9 \pm 12.5$ & $45.0 \pm 9.0$ \\
\hline Kayacan $2002^{28}$ & 20 & 20 & $38.7 \pm 7.8$ & $38.7 \pm 7.8$ & NR & NR & $48.9 \pm 12.5$ & $45.0 \pm 9.0$ \\
\hline Keita $2003^{29}$ & 15 & 16 & $31.8 \pm 5.6$ & $32.5 \pm 5.2$ & NR & NR & $68.2 \pm 49.6$ & $56.5 \pm 35.6$ \\
\hline Shalan $2002^{30}$ & 60 & 60 & $31.1 \pm 4.2$ & $29.8 \pm 3.7$ & NR & $N R$ & NR & $N R$ \\
\hline
\end{tabular}

Note: Data are reported as mean \pm SD.

Abbreviations: NR, not reported; BMI, body-mass index.

limitation of this previous meta-analysis was the relatively small number of patients. Therefore, analyzing the data nine years later, we were able to include far more trials in the present meta-analysis to provide large-scale evidence of the effect of intraperitoneal bupivacaine on postoperative pain.

Multiple trials have shown a benefit to the subcutaneous injection of bupivacaine into tissues around the wound in a technique similar to using lidocaine for local short-acting anesthesia. ${ }^{26,32-34}$ These studies have ranged from small cohort studies to large RCT's and looked at fractionated and unfractionated forms, as well as preoperative and postoperative administration. ${ }^{33-36}$ Therefore, it would make sense that intraperitoneal bupivacaine could also be beneficial.

Lastly, a major impetus of this study was the sediment from our authors that postoperative pain from gynecologic surgeries, especially laparoscopic and vaginal hysterectomy, from the perspective of any experienced surgery is intra-abdominal pain. Examination of these patients soon after surgery shows tender abdomens that do not tolerate deep examination, it does not show point tenderness to superficial wounds, as one might commonly see, for example, with a herpes or shingles lesion. Therefore the superiority of intraperitoneal bupivacaine to subcutaneous or local injection, to our authors, seems obvious.

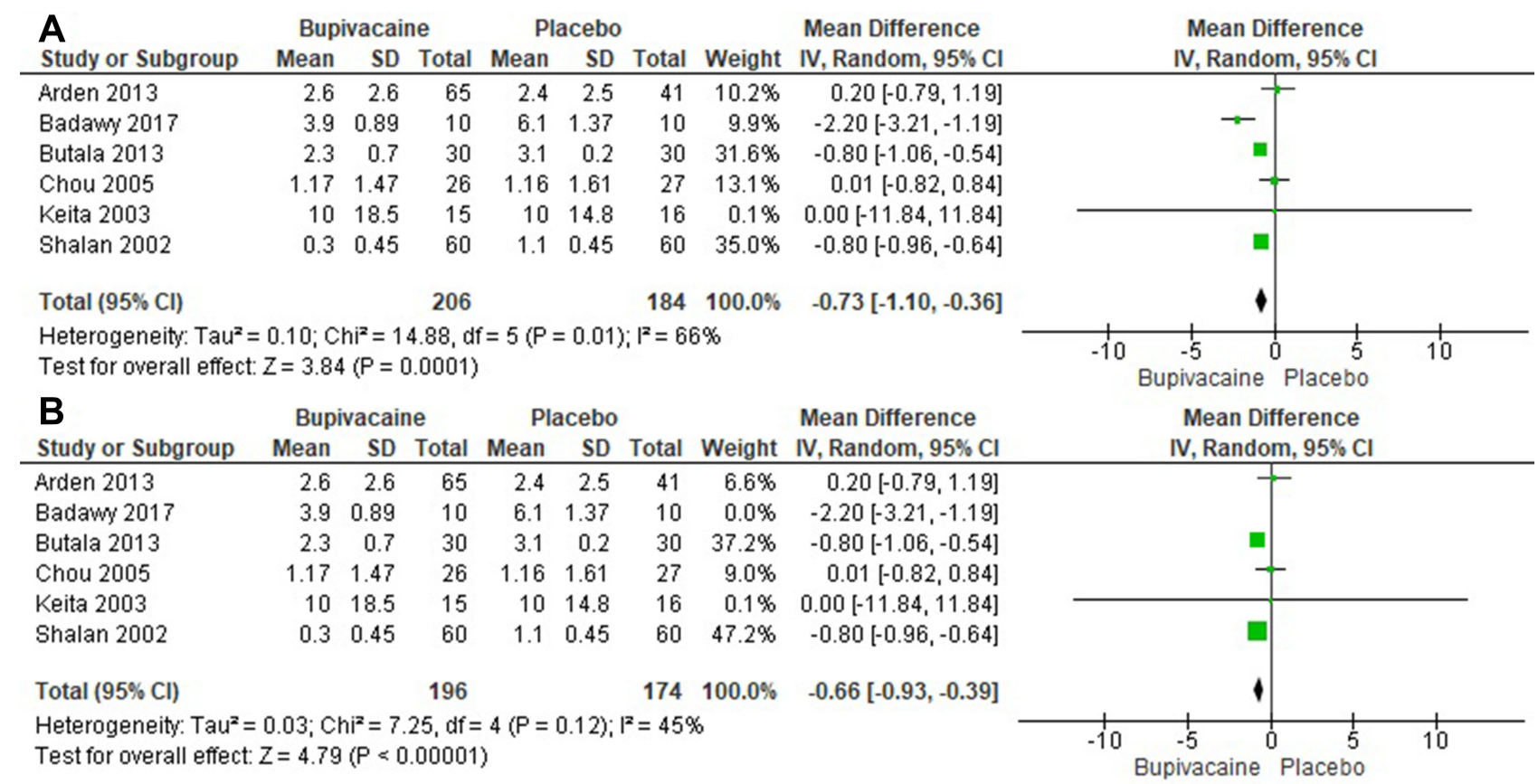

Figure 2 (A and $\mathbf{B}$ ) show forest plots of patient pain at 24 hours after surgery, before (A) and after (B) removing Badawy et al 2017 to solve heterogeneity. 


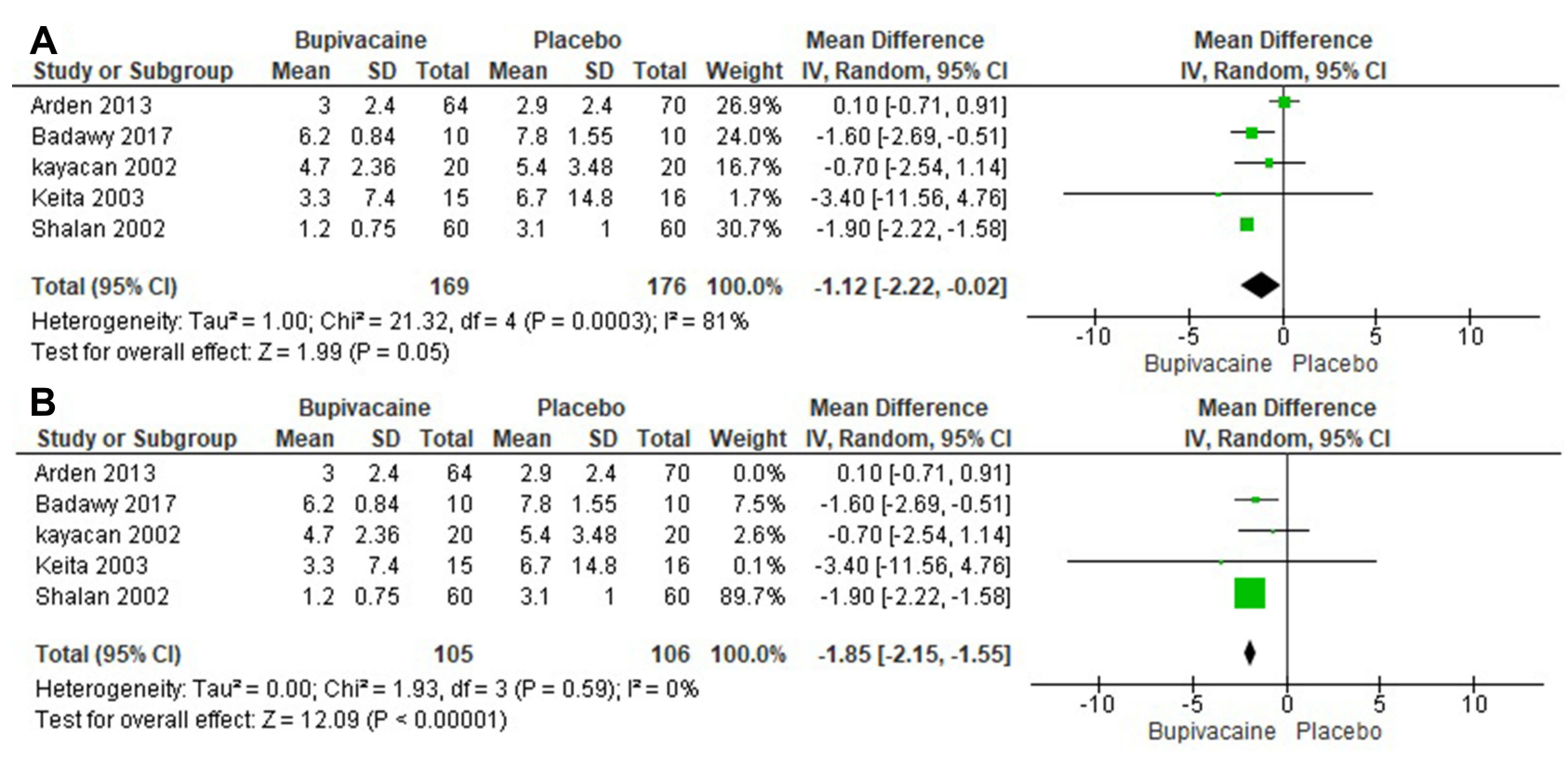

Figure 3 (A and B) show forest plots of patient pain at 6 hours after surgery, before (A) and after (B) removing Arden et al 2013 to solve heterogeneity.

\begin{tabular}{|c|c|c|c|c|c|c|c|c|c|c|c|}
\hline \multirow[b]{2}{*}{ Study or Subgroup } & \multicolumn{3}{|c|}{ Bupivacaine } & \multicolumn{3}{|c|}{ Placebo } & \multicolumn{3}{|c|}{ Mean Difference } & \multirow{2}{*}{$\begin{array}{l}\text { Mean Difference } \\
\text { N, Fixed, } 95 \% \mathrm{Cl}\end{array}$} & \\
\hline & Mean & SD & Total & Mean & SD & Total & Weight & IV, Fixed, $95 \% \mathrm{Cl}$ & & & \\
\hline Arden 2013 & 22.9 & 3.2 & 76 & 23.4 & 3.2 & 80 & $98.8 \%$ & $-0.50[-1.50,0.50]$ & & & \\
\hline Chou 2005 & 41.27 & 16.6 & 26 & 36.56 & 17.86 & 27 & $1.2 \%$ & $4.71[-4.57,13.99]$ & & & \\
\hline Total $(95 \% \mathrm{Cl})$ & & & 102 & & & 107 & $100.0 \%$ & $-0.44[-1.44,0.56]$ & & & \\
\hline $\begin{array}{l}\text { Heterogeneity: } \mathrm{Chi}^{2} \\
\text { Test for overall effect }\end{array}$ & $\begin{array}{l}1.20, d f \\
Z=0.88\end{array}$ & $\begin{array}{l}=1(P \\
(P=0\end{array}$ & $\begin{array}{l}=0.27) \\
1.39 \text { ) }\end{array}$ & $i^{2}=1$ & & & & & -10 & $\begin{array}{llr}-5 & 0 & 5 \\
\text { pivacaine } & \text { Placebo }\end{array}$ & 10 \\
\hline
\end{tabular}

Figure 4 Shows the forest plot of the outcomes for length of hospital stay.

\begin{tabular}{|c|c|c|c|c|c|c|c|c|c|c|c|c|}
\hline \multirow{2}{*}{$\mathbf{A}_{\text {Study or Subgroup }}$} & \multicolumn{3}{|c|}{ Bupiracaine } & \multicolumn{3}{|c|}{ Placebo } & \multicolumn{3}{|c|}{ Mean Difference } & \multirow{2}{*}{\multicolumn{2}{|c|}{$\begin{array}{l}\text { Mean Difference } \\
\text { IV, Random, } 95 \% \mathrm{Cl}\end{array}$}} & \\
\hline & Mean & SO & Total & Mean & SD & Total & Weight & N, Random, $95 \% \mathrm{Cl}$ & & & & \\
\hline Badxwy 2017 & 360 & 826 & 10 & 192 & 888 & 10 & $282 \%$ & $188.00|91.98,244.02|$ & & & $\because-$ & \\
\hline Butala 2013 & 270.8 & 56.8 & 30 & 75 & 489 & 30 & $350 \%$ & $195.60(188.78,222.22)$ & & & $=$ & \\
\hline Karsli 2003 & 93 & 29 & 20 & 16 & 3.1 & 20 & $358 \%$ & $7700[63.88,90.32]$ & & & $=$ & \\
\hline Total $(95 \% \mathrm{Cl})$ & & & 60 & & & 60 & $100.0 \%$ & $145.08[51.37,238.79]$ & & & & \\
\hline \multicolumn{9}{|c|}{ 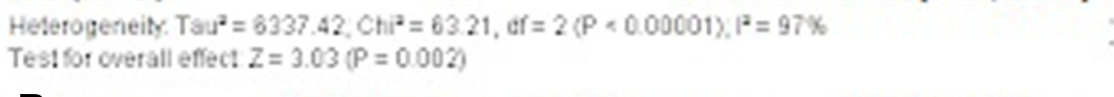 } & $\frac{1}{.500}$ & -250 Placebo & Bupivacaine & $500^{\circ}$ \\
\hline $\mathbf{B}$ & \multicolumn{3}{|c|}{ Bupivacaine } & \multicolumn{3}{|c|}{ Placebo } & \multicolumn{2}{|r|}{ Mean Difference } & \multirow{2}{*}{\multicolumn{4}{|c|}{$\begin{array}{l}\text { Mean Detterence } \\
\mathrm{N} \text {, Random, } 95 \mathrm{~N} \mathrm{Cl}\end{array}$}} \\
\hline Study or Subgroup & Moan & SD & Total & Mean & SD & Total & Weight & IV, Random, 95N Cl & & & & \\
\hline Badav// 2017 & 350 & 84.6 & 10 & 192 & 88.8 & 10 & $11.1 \%$ & $168.00[91.98,284.02]$ & & & $=$ & \\
\hline Butala 2013 & 270.6 & 56.8 & 30 & 75. & 48.9 & 30 & $88.9 \%$ & $195.60[168.78,222.42]$ & & & & \\
\hline Karsli 2003 & 93 & 28 & 20 & 16 & 9.1 & 20 & $0.0 \%$ & $77.00[53.68,90.32]$ & & & & \\
\hline Total $(95 \% \mathrm{Cl})$ & & & 40 & & & 40 & $100.0 \mathrm{~s} \quad 1$ & $192.54[167.25,217.84]$ & & & $\bullet$ & \\
\hline $\begin{array}{l}\text { Heterogeneity Tau* } \\
\text { Test for omerall effect: }\end{array}$ & $\begin{array}{l}0.00 ; \mathrm{Ch} \\
Z=14.92\end{array}$ & $\begin{array}{l}* \\
2(P<\end{array}$ & $\begin{array}{l}45, \mathrm{df}= \\
0.0000\end{array}$ & $1(P=0$ & $0.50) ; 1$ & $r=0 \%$ & & & -500 & -250 Placebo ${ }^{0}$ & $\begin{array}{r}250 \\
\text { Bupiracaine }\end{array}$ & 500 \\
\hline
\end{tabular}

Figure 5 (A and B) show forest plots of the elapsed time prior to the first non-local analgesic dose, before (A) and after (B) removing Karsli et al 2003 to solve heterogeneity. 


\section{Strengths}

The major strength of our study was our inclusion of only those clinical trials which were properly randomized and controlled for. According to the GRADE guideline, this should provide the highest level of evidence. Another strength of our study was the risk of bias, as all of the included studies were judged to be at a low risk of bias, almost universally in all categories. Next, our patient sample size in the included studies was quite large, including 534 total patients. This speaks to higher quality evidence. Lastly, we were able to solve the heterogeneity that was found in our results using only appropriate, recognized techniques that can be found within Cochrane's handbook. ${ }^{22}$

\section{Limitations}

Although the biggest single limitation facing this study was the heterogeneity in some of our outcomes, we were able to track down the individual attributing factors and solve the heterogeneity in all cases. Another limitation includes the inherent weaknesses of subjective pain scales such as the VAS, ${ }^{37}$ although our authors do not have a better system to propose at this time. Lastly, although our goal was to find the existence of an effect, the fact that the doses used were not standardized is another weakness of our study.

\section{Conclusion}

We conclude that intraperitoneal bupivacaine significantly reduced the VAS score for pain compared with that of the placebo at 6 and 24 hours. This efficacy may lead surgeons to consider intraperitoneal administration in laparoscopic gynecologic surgical procedure. Further studies are needed to determine the best local anesthetic and route of administration for minimization of postoperative pain in laparoscopic gynecologic surgery.

\section{Data Sharing Statement}

All supporting data is included or referenced in this manuscript. The authors have no additional data used in this study.

\section{Ethics Approval and Consent to Participate}

This Manuscript has been reviewed by the institutional IRB board at Marchand Institute and was found to be exempt from IRB review (March 2021). Data used was exempt from consent to participate or publish secondary to the nature of the study being a systematic review, retrospectively looking at previously published data.

\section{Consent to Publish}

Data used was exempt from consent to participate or publish secondary to the nature of the study being a systematic review, retrospectively looking at previously published data.

\section{Patient Consent}

Not applicable to systematic review.

\section{Acknowledgments}

The Marchand Institute for Minimally Invasive Surgery would like to acknowledge the efforts of all of the students, researchers, residents and fellows at the institute who put their time and effort into these projects without compensation, only for the betterment of women's health. We firmly assure them that the future of medicine belongs to them.

\section{Author Contributions}

All authors contributed to data analysis, drafting or revising the article, have agreed on the journal to which the article will be submitted, gave final approval of the version to be published, and agree to be accountable for all aspects of the work.

\section{Funding}

No funding was received for this study.

\section{Disclosure}

The authors declare no competing interests.

\section{References}

1. Ismail S, Siddiqui AS, Rehman A. Postoperative pain management practices and their effectiveness after major gynecological surgery: an observational study in a tertiary care hospital. J Anaesthesiol Clin Pharmacol. 2018;34(4):478. doi:10.4103/joacp.JOACP 38717

2. Brandsborg B, Nikolajsen L, Hansen CT, Kehlet H, Jensen TS. Risk factors for chronic pain after hysterectomy: a nationwide questionnaire and database study. Anesthesiology. 2007;106(5):1003-1012. doi:10.1097/01.anes.0000265161.39932.e8

3. Lovich-Sapola J, Smith CE, Brandt CP. Postoperative pain control. Surg Clin North Am. 2015;95(2):301-318. doi:10.1016/j. suc. 2014.10 .002

4. Garimella V, Cellini C. Postoperative pain control. Clin Colon Rectal Surg. 2013;26(03):191-196. doi:10.1055/s-0033-1351138

5. Gan TJ. Poorly controlled postoperative pain: prevalence, consequences, and prevention. J Pain Res. 2017;10:2287-2298. doi:10.2147/JPR.S144066 
6. Kinsella S, Gibbison B. Postoperative analgesia for gynecological laparoscopy. Saudi J Anaesth. 2009;3(2):26. doi:10.4103/1658354X.57883

7. Hah JM, Bateman BT, Ratliff J, Curtin C, Sun E. Chronic opioid use after surgery: implications for perioperative management in the face of the opioid epidemic. Anesth Analg. 2017;125(5):1733-1740. doi:10.1213/ANE.0000000000002458

8. Winacoo JN, Maykel JA. Operative anesthesia and pain control. Clin Colon Rectal Surg. 2009;22(01):041-046. doi:10.1055/s-00291202885

9. Elsevier H, Cannada LK. Management of pain associated with fractures. Curr Osteoporos Rep. 2020;18(3):130-137. doi:10.1007/ s11914-020-00578-3

10. Shady NW, Sallam HF, Ali SS, Abbas AM. Effect of intra-peritoneal and incisional port site lidocaine on pain relief after gynecological laparoscopic surgery: a randomized controlled study. Middle East Fertil Soc J. 2018;23(1):63-67. doi:10.1016/j.mefs.2017.08.005

11. Decosterd I, Woolf CJ. Spared nerve injury: an animal model of persistent peripheral neuropathic pain. Pain. 2000;87(2):149-158. doi:10.1016/S0304-3959(00)00276-1

12. Huygen FJPM, Kallewaard JW, Nijhuis H, et al. Effectiveness and safety of dorsal root ganglion stimulation for the treatment of chronic pain: a pooled analysis. Neuromodulation. 2020;23(2):213-221. doi:10.1111/ner.13074

13. Pete DD, D’Souza MS. Local anesthetics. In: Side Effects of Drugs Annual. Elsevier; 2020.

14. Cherobin ACFP, Tavares GT. Safety of local anesthetics. An Bras Dermatol. 2020;95(1):82-90. doi:10.1016/j.abd.2019.09.025

15. Belfrage P, Raabe N, Thalme B, Berlin A. Lumbar epidural analgesia with bupivacaine in labor. Determination of drug concentration and $\mathrm{pH}$ in fetal scalp blood, and continuous fetal heart rate monitoring. Am J Obstet Gynecol. 1975;121(3):360-365.

16. Moore DC, Bridenbaugh LD, Bridenbaugh PO, Tucker GT. Bupivacaine: a review of 2077 cases. J Am Med Assoc. 1970;214 (4):713. doi:10.1001/jama.1970.03180040021003

17. Mogensen T, Eliasen K, Ejlersen E, Vegger P, Nielsen IK, Kehlet H. Epidural clonidine enhances postoperative analgesia from a combined low-dose epidural bupivacaine and morphine regimen. Anesth Analg. 1992;75(4):607-610. doi:10.1213/00000539199210000-00025

18. Asantila R, Eklund P, Rosenberg PH. Continuous epidural infusion of bupivacaine and morphine for postoperative analgesia after hysterectomy. Acta Anaesthesiol Scand. 1991;35(6):513-517. doi:10.1111/j.1399-6576.1991.tb03339.x

19. Moher D, Liberati A, Tetzlaff J, et al. Preferred reporting items for systematic reviews and meta-analyses: the PRISMA statement (Chinese edition). $J$ Chin Integr Med. 2009;7(9):889-896. doi:10.3736/jcim20090918

20. Higgins JPT, Green S. Cochrane Handbook for Systematic Reviews of Interventions: Cochrane Book Series. John Wiley \& Sons; Vol. Version 5; 2008:1.

21. Higgins JPT, Thompson SG, Deeks JJ, Altman DG. Measuring inconsistency in meta-analyses. $\mathrm{Br}$ Med $J . \quad 2003 ; 327$ (7414):557-560. doi:10.1136/bmj.327.7414.557

22. Higgins JP, Altman DG. Assessing Risk of Bias in Included Studies. In: Cochrane Handbook for Systematic Reviews of Interventions: Cochrane Book Series. Wiley-Blackwell; 2008.

23. Arden D, Seifert E, Donnellan N, Guido R, Lee T, Mansuria S. Intraperitoneal instillation of bupivacaine for reduction of postoperative pain after laparoscopic hysterectomy: a Double-Blind Randomized Controlled Trial. J Minim Invasive Gynecol. 2013;20(5):620-626. doi:10.1016/j.jmig.2013.03.012
24. Badawy AM. intra-peritoneal analgesia to reduce pain after laparoscopic hysterectomy. Int J Reprod Contracept Obstet Gynecol. 2017;6(8):3235. doi:10.18203/2320-1770.ijrcog20173444

25. Karsli B, Kayacan N, Zorlu G, Arici G, Erman M. The effects of intra-peritoneal tramadol, tenoxicam and bupivacaine on pain relief after laparoscopic gynecological procedures. Pain Clin. 2003;15 (3):281-286. doi:10.1163/156856903767650808

26. Butala BP, Shah VR, Nived K. Randomized double blind trial of intra-peritoneal instillation of bupivacaine and morphine for pain relief after laparoscopic gynecological surgeries. Saudi J Anaesth. 2013;7(1):18-23. doi:10.4103/1658-354X.109800

27. Chou YJ, Ou YC, Lan KC, Jawan B, Chang SY, Kung FT. Preemptive analgesia installation during gynecologic laparoscopy: a randomized trial. J Minim Invasive Gynecol. 2005;12(4):330-335. doi:10.1016/j.jmig.2005.05.005

28. Kayacan N, Arici G, Karsli B, Zorlu G, Erman M. The analgesic efficacy of intra-peritoneal local anaesthetic instillation after laparoscopic gynaecological procedures. Gynaecol Endosc. 2002;11 (6):377-381. doi:10.1111/j.1365-2508.2002.00559.x

29. Keita H, Benifla JL, Le Bouar V, et al. Prophylactic ip injection of bupivacaine and/or morphine does not improve postoperative analgesia after laparoscopic gynecologic surgery. Can J Anesth. 2003;50 (4):362-367. doi:10.1007/BF03021033

30. Shalan H, Badawy A, Yousef H, Nazar M. Effect of intra-peritoneal bupivacaine on postoperative pain following laparoscopic pelvic surgery. Gynaecol Endosc. 2002;11(6):371-375. doi:10.1111/j.13652508.2002.00557.x

31. Marks JL, Ata B, Tulandi T. Systematic review and meta analysis of intra-peritoneal instillation of local anesthetics for reduction of pain after gynecologic laparoscopy. J Minim Invasive Gynecol. 2012;19 (5):545-553. doi:10.1016/j.jmig.2012.04.002

32. Barawi SA, Ahmed Saleh S. Local injection of bupivacaine hydrochloride to reduce postoperative pain in obstetrical and gynaecological surgical incision. J Anesth Clin Res. 2017;8(10). doi:10.4172/ 2155-6148.1000768

33. Hortu I, Turkay U, Terzi H, et al. Impact of bupivacaine injection to trocar sites on postoperative pain following laparoscopic hysterectomy: results from a prospective, multicentre, double-blind randomized controlled trial. Eur J Obstet Gynecol Reprod Biol. 2020;252:317-322. doi:10.1016/j.ejogrb.2020.07.007

34. Kutay Yazici K, Kaya M, Aksu B, Ünver S. The effect of perioperative lidocaine infusion on postoperative pain and postsurgical recovery parameters in gynecologic cancer surgery. Clin J Pain. 2021;37 (2):126-132. doi:10.1097/AJP.0000000000000900

35. Pasqualucci A, De Angelis V, Contardo R, et al. Preemptive analgesia: intra-peritoneal local anesthetic in laparoscopic cholecystectomy: a randomized, double-blind, placebo-controlled study. Anesthesiology. 1996;85(1):11-20. doi:10.1097/00000542199607000-00003

36. Labaille T, Mazoit JX, Paqueron X, Franco D, Benhamou D. The clinical efficacy and pharmacokinetics of intra-peritoneal ropivacaine for laparoscopic cholecystectomy. Anesth Analg. 2002;94 (1):100-105.

37. Katz J, Melzack R. Measurement of pain. Surg Clin North Am. 1999;79(2):231-252. doi:10.1016/S0039-6109(05)70381-9 


\section{Publish your work in this journal}

The Journal of Pain Research is an international, peer reviewed, open access, online journal that welcomes laboratory and clinical findings in the fields of pain research and the prevention and management of pain Original research, reviews, symposium reports, hypothesis formation and commentaries are all considered for publication. The manuscript management system is completely online and includes a very quick and fair peer-review system, which is all easy to use. Visit http:// www.dovepress.com/testimonials.php to read real quotes from published authors.

Submit your manuscript here: https://www.dovepress.com/journal-of-pain-research-journal 